\title{
Advances and perspective of the immunotherapy for relapsed/refractory multiple myeloma (interview)
}

\section{S.V. Semochkin}

P.A. Hertzen Moscow Oncology Research Institute - branch of the National Medical Research Radiological Center, Ministry of Health of Russia; $32^{\text {nd }}$ Botkinskiy Proezd, Moscow 125284, Russia;

N.I. Pirogov Russian National Research Medical University, Ministry of Health of Russia; 1 Ostrovityanova St., Moscow 117997, Russia

Cont a c t s: Sergey Vyacheslavovich Semochkin semochkin_sv@rsmu.ru

For citation: Semochkin S.V. Advances and perspective of the immunotherapy for relapsed/refractory multiple myeloma. Onkogematologiya $=$ 0ncohematology 2022;17(1):43-52. (In Russ.). DOI: 10.17650/1818-8346-2022-17-1-43-52.

Глубокоуважаемый Сергей Вячеславович, позвольте поблагодарить Вас за возможность обсудить некоторые вопросы, касающиеся иммунотерапии рецидивирующей/рефрактерной множественной миеломы (РРММ). За последнее десятилетие фармакотерапия множественной миеломы (ММ) прошла новый эволюционный этап, приближающий нас к излечению этого тяжелого заболевания. Решающее значение при выборе терапии рецидивов ММ имеют особенности предшествующего лечения, степень агрессивности рецидива, наличие сопутствующих заболеваний, мнение пациента и, конечно, обеспеченность отдельными медицинскими опциями. В настоящее время нам доступны несколько ингибиторов протеасомы, иммуномодуляторов и моноклональных терапевтических антител. При этом именно с иммунотерапией мы связываем дальнейшие перспективы лечения ММ. Комбинация нескольких препаратов с моноклональными антителами повышает вероятность достижения глубокого противоопухолевого ответа и пролонгирует общую выживаемость (ОВ). Применение многокомпонентных схем сопряжено с большей токсичностью, которую необходимо уметь предупреждать и контроли- ровать. Постоянно увеличивающийся спектр новых возможностей усложняет выбор оптимального режима лечения конкретного пациента. Не совсем очевидна наилучшая последовательность смены отдельных схем и препаратов по мере развития заболевания: от впервые диагностированного до полностью рефрактерного. Этим проблемам я предлагаю посвятить нашу беседу.

Для начала давайте обсудим текущее состояние вопроса лечения РРММ. Каким Вы видите терапевтический профиль пациентов с ММ в нашей стране?

Глубокоуважаемая Первин Айдыновна, в первую очередь разрешите поблагодарить Вас за возможность со страниц одного из авторитетнейших российских журналов пообщаться с профессиональным гематологическим сообществом нашей страны.

С началом широкого применения первых двух, по сути, революционных препаратов, бортезомиба и леналидомида, в 2000-х годах произошло качественное улучшение показателей ОВ пациентов с ММ. Состояние проблемы лечения ММ в России в целом неоднократно представляла профессор Л.П. Менделеева. По результатам проспективного наблюдательного 
исследования НМИЦ гематологии, включившего данные более чем 3 тыс. первичных пациентов из половины регионов нашей страны, в основном в 1-й линии в 2015-2018 гг. получали бортезомиб-содержашие комбинации (92 \% больных), во 2-й линии - схемы с леналидомидом (70 \%). Количество выполняемых аутологичных трансплантаций гемопоэтических стволовых клеток по-прежнему невелико и покрывает менее $20 \%$ потребностей пациентов, подходящих для реализации этой опции [1]. В период 2006-2016 гг. 5-летняя ОВ в отдельных регионах России составляла около 47$54 \%$. К сожалению, пока нет доступных популяционных данных, показывающих, как сказалось на ОВ включение в 2019 г. даратумумаба в перечень препаратов для лечения заболеваний, которые относятся к высокозатратным нозологиям (В3Н). Доля пациентов, получающих анти-CD38-моноклональные антитела, очевидно, растет. Если некоторое время назад мы большое внимание уделяли обсуждению вопроса двойной рефрактерности - ситуации, при которой новые антитела оказались очень эффективны [2], то на повестке дня встала уже проблема рефрактерности к 3 классам препаратов - одновременной устойчивости к иммуномодуляторам, ингибиторам протеасомы и анти-CD38-моноклональным антителам. В подобной ситуации медиана выживаемости без прогрессирования (ВБП) не превышает 3-4 мес, и простого решения этой проблемы пока нет [3].

В прошлом году противоопухолевый иммуномодулятор 3-го поколения - помалидомид - был одобрен для включения в программу 14 ВЗН для лечения ММ. Помимо оригинального препарата Имновид (Celgene, BMS), на рынке присутствует 2 отечественных дженерика: Помалидомид-ТЛ (Р-Фарм) и Иматанго (Рафарма). В связи с расширением доступа к препарату мне представляется важным напомнить коллегам особенности его применения. Мой первый вопрос касается показаний $\kappa$ назначению. Для какой целевой категории пациентов с ММ предназначен помалидомид?

Помалидомид был зарегистрирован в России еще в 2013 г. для лечения взрослых пациентов, которые получили по крайней мере 2 курса терапии, включавших леналидомид и бортезомиб, и у которых отмечалось прогрессирование непосредственно на фоне последней линии терапии или в пределах 60 дней после ее окончания. Таким образом, речь идет о пациентах с той самой двойной рефрактерностью. В общем, показания такие же, как у даратумумаба в монорежиме. Действие помалидомида проявляется у пациентов с рефрактерностью к леналидомиду, но не наоборот [4].

Помалидомид назначают в стартовой дозе 4 мг внутрь с 1-го по 21-й день каждого 28-дневного цикла в комбинации с дексаметазоном в дозе 40 мг 1 раз в неделю (схема 1-21/28) [5]. Пациентам старше 75 лет доза дексаметазона должна быть снижена до 20 мг в неделю. В зависимости от выраженности цитопений в процессе терапии возможна редукция дозы помалидомида. Коррекция дозы помалидомида не требуется при любой степени тяжести миеломной нефропатии, поскольку он метаболизируется преимущественно внепочечным путем. Однако во время гемодиализа концентрация помалидомида в крови снижается на $30-40 \%$, в связи с чем препарат принимают после процедуры.

С какими нежелательными явлениями чаще всего приходится сталкиваться в процессе лечения? Есть ли потребность в снижении стартовой дозы помалидомида у ослабленных пациентов или в случае значимых коморбидностей?

Самыми частыми побочными эффектами, которые наблюдаются при назначении помалидомида, являются миелосупрессия и инфекционные осложнения, в первую очередь пневмонии. Профилактика тромботических осложнений такая же, как при назначении леналидомида (ацетилсалициловая кислота, низкомолекулярные гепарины), риск тромбозов при профилактике не превышает 2-3\%.

Нейтропения. Перед началом терапии абсолютное число нейтрофилов должно быть $>1,0 \times 10^{9} /$ л. В течение первых 2 мес общий анализ крови рекомендуется выполнять каждые 1-2 нед, далее - ежемесячно. У большинства больных нейтропения возникает уже в процессе проведения 1-го цикла терапии. При снижении абсолютного числа нейтрофилов до $<0,5 \times 10^{9} / л$ следует добавить гранулоцитарный колониестимулирующий фактор (Г-КСФ), например, 3 дня вводить филграстим в дозе 5 мкг/кг. В последующих циклах Г-КСФ назначают с 22-го по 24-й день каждого 28 -дневного цикла. В случае фебрильной нейтропении и других значимых инфекций терапию помалидомидом временно прекрашают. После восстановления абсолютного числа нейтрофилов $>1,0 \times 10^{9} /$ л ее возобновляют с редукцией дозы помалидомида на 1 мг от предыдущей.

Тромбоцитопения. Перед началом терапии число тромбоцитов должно быть $>75 \times 10^{9} /$ л или $>30 \times 10^{9} /$ л в случае, если плазматические клетки составляют $>50 \%$ ядросодержащих клеток костного мозга. При количестве тромбоцитов ниже пороговых значений применение помалидомида также возможно, если реально проводить адекватную заместительную терапию тромбоконцентратом. Прием помалидомида следует прекратить при снижении числа тромбоцитов $<25 \times 10^{9} /$ л. При восстановлении числа тромбоцитов $>50 \times 10^{9} / л$ лечение возобновляют в дозе на 1 мг меньше предыдущей. Согласно данным Федеральной службы по надзору в сфере здравоохранения помалидомид производится в виде капсул по 4 и 2 мг для приема внутрь. Соответственно, в России есть возможность перехода с дозы 4 мг/сут на сниженную - 2 мг/сут (рис. 1).

Инфекционные осложнения. Всем пациентам рекомендована вакцинация против пневмококковой 


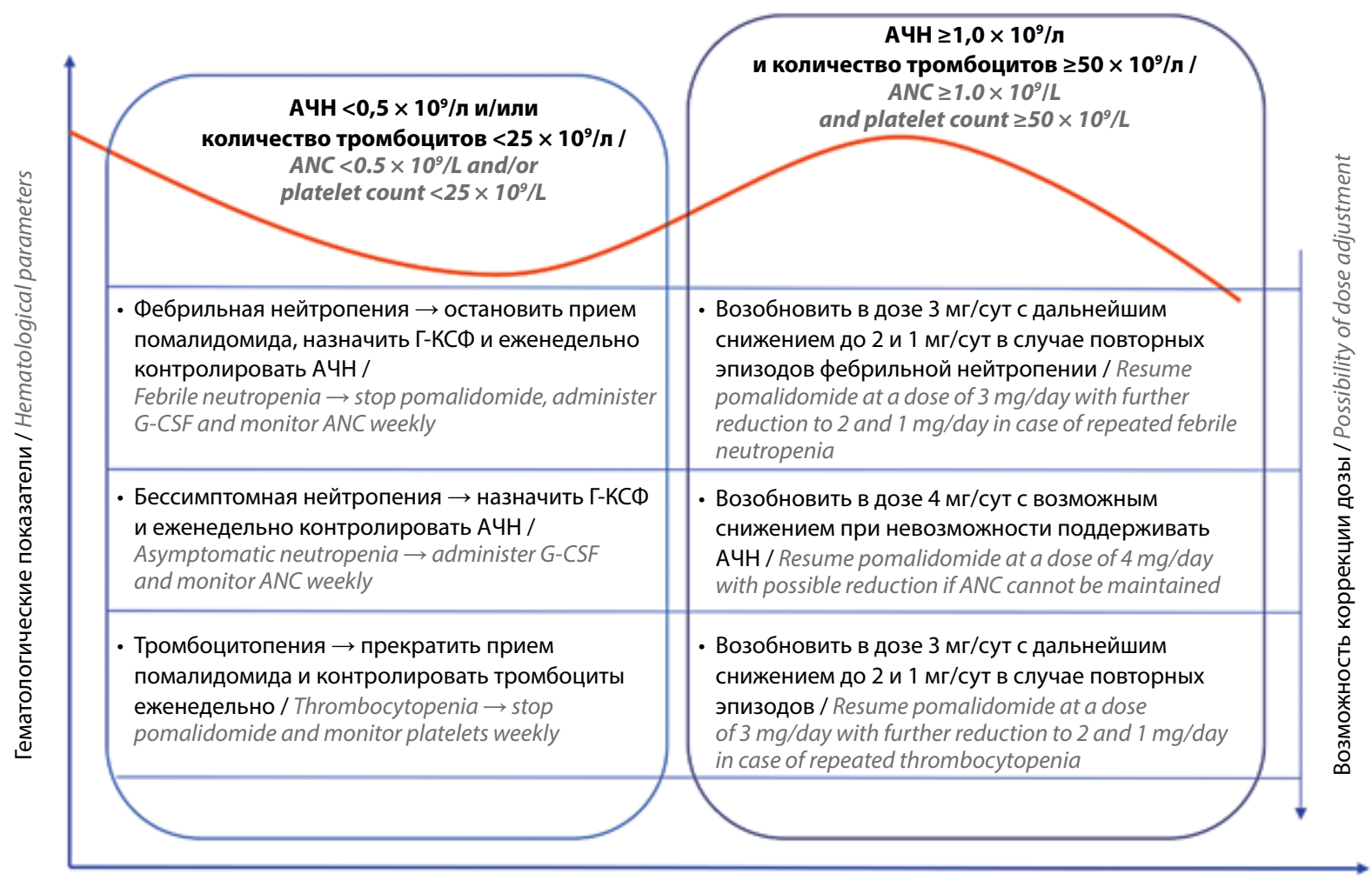

Время (циклы терапии) / Time (therapy cycles)

Рис. 1. Алгоритм коррекции дозы помалидомида. АЧН - абсолютное число нейтрофилов; Г-КСФ - гранулоцитарный колониестимулирующий фактор

Fig. 1. Algorithm for adjusting the pomalidomide dose. ANC - absolute neutrophil count; G-CSF-granulocyte colony stimulating factor

инфекции, новой короновирусной инфекции COVID-19 и ежегодно против гриппа [6]. В первые 3 мес приема помалидомида показана профилактика инфекций с помощью антибактериальных препаратов. У пациентов с высоким риском инфекционных осложнений прием оральных антибактериальных препаратов возможен на протяжении всего периода лечения. Рекомендовано применение сульфаметоксазола/триметоприма, амоксициллина или фторхинолонов (норфлоксацин, офлоксацин, левофлоксацин, моксифлоксацин). При назначении строгих ингибиторов СYР1А2, таких как ципрофлоксацин и эноксацин, необходимо снижение дозы помалидомида на $50 \%$, т.е. до 2 мг/сут. При развитии инфекционных осложнений терапию помалидомидом следует прекратить до стабилизации состояния пациента. Важными в профилактике инфекционных осложнений являются тщательный мониторинг количества нейтрофилов, применение при необходимости Г-КСФ и своевременная коррекция дозы помалидомида. При этом следует помнить, что большинство случаев пневмоний возникает вне периодов нейтропении [7].

В качестве стартовой дозы помалидомида в большинстве случаев следует придерживаться 4 мг/сут. В случае, если исходная цитопения обусловлена массивной инфильтрацией костного мозга плазматическими клетками (>50 \%), важно максимально быстро снизить опухолевую нагрузку, что даст возможность восстановить гемопоэз, поэтому выгодно использовать полную дозу. Если же цитопения связана с истощением резервов костномозгового кроветворения в результате проведения большого количества линий химиотерапии, вопрос остается открытым. Нельзя дать четких рекомендаций. По данным исследований II фазы, противоопухолевая активность помалидомида проявляется при дозе 2 мг/сут, а максимально переносимой считается доза 4 мг/сут. Миелотоксичность помалидомида в целом выше, чем леналидомида. Доза помалидомида 4 мг, естественно, агрессивнее 3 и 2 мг.

В 1-м исследовании II фазы $(n=60)$ помалидомид назначали в дозе 2 мг/сут с дексаметазоном (схема 1-28/28). У пациентов, у которых не был достигнут ответ при использовании помалидомида 2 мг/сут $(n=23)$, доза была увеличена до 4 мг/сут. В целом ответ был получен у 38 (63 \%) пациентов [8]. В этом исследовании не было требования включать больных с рефрактерностью к леналидомиду, собственно, поэтому и получена такая высокая частота общего ответа.

Во 2-м исследовании уже набирали пациентов с условием обязательной рефрактерности к леналидомиду $(n=34)$. Пациенты получали помалидомид по 2 мг 21 день в комбинации с дексаметазоном (схема $1-21 / 28)$. Дозу помалидомида в зависимости от ответа не изменяли. Ответ на лечение получен у $32 \%$ больных. Медиана ВБП составила 4,8 мес (95\% доверительный интервал (ДИ) 2,7-10,1 мес) [9]. 
Наконец, в 3-м исследовании участвовали только пациенты с двойной рефрактерностью $(n=70)$. Последовательно было набрано 2 группы по 35 пациентов. Больные 1-й группы получали помалидомид в дозе 2 мг/сут, пациенты 2-й группы - 4 мг/сут, все в комбинации с дексаметазоном (схема $1-28 / 28$ ). В этом исследовании не было выявлено достоверных различий между группами ни в частоте общего ответа (26 \% против $28 \%$ ), ни в показателях ВБП (медиана 6,5 мес (95\% ДИ 3,9-8,9 мес) против 3,2 мес (95 \% ДИ 1,9$8,6 \mathrm{мес)})$ [10].

Доза помалидомида 4 мг/сут (схема 1-21/28) является максимальной по переносимости. При использовании дозы 5 мг/сут отмечается неприемлемо высокая частота фебрильной нейтропении. Доза 4 мг/сут была выбрана для исследований ІІІ фазы, включая все новые триплеты. С учетом того что до $30 \%$ больных в реальной практике в силу плохого соматического состояния и сопутствующих заболеваний не могут участвовать в проспективных исследованиях, мы не знаем, как такие пациенты переносят схему Pd (помалидомид, дексаметазон). Вполне возможно, что им может потребоваться меньшая стартовая доза (2 мг) с последующей эскалацией при хорошей переносимости, подобно тому, как делали в ранних исследованиях.

Одним из важных факторов, определяющих неблагоприятное биологическое поведение РРММ, является рефрактерность к леналидомиду. При этом сам факт приобретенной рефрактерности не всегда очевиден. Например, у одного пациента отмечается прогрессирование на фоне комбинации Rd (леналидомид, дексаметазон) с дозой леналидомида 25 мг/сут, а у другого - на фоне поддерживающей терапии с дозой леналидомида 10 мг без дексаметазона. Очевидно, что это разные клинические ситуации. Как определить, ито у пациента истинная рефрактерность к леналидомиду?

Действительно, факт рефрактерности к леналидомиду является критическим биологическим событием. По крайней мере, при использовании текущего набора опций это непреложный факт. В плане определения истинной рефрактерности к леналидомиду очень показательна работа, опубликованная нашими греческими коллегами [11]. Схему Рd получали в общей сложности 147 пациентов с РРММ, в том числе 135 (92\%) больных с рефрактерностью к последней линии терапии с леналидомидом. Авторы проанализировали эффективность схемы Рd в зависимости от особенностей предшествующего применения леналидомида. Оказалось, что не было никакой разницы, получали пациенты леналидомид в дозе 25 мг/сут или в сниженных дозах 5-15 мг/сут (рис. 2) [11].

Результаты оказались лучше у пациентов с длительностью использования леналидомида $\geq 12$ мес, чем у тех, кто принимали его менее 12 мес: медиана ВБП 7,8 мес против 3,2 мес $(p=0,023)$; ОВ 16,5 мес против 7,9 мес $(p=0,005)$. Ответ также был лучше у пациентов, которые $\geq 18$ мес до назначения $\mathrm{Pd}$ не получали иммуномодуляторы: медиана ВБП 10,3 мес против 3,9 мес $(p=0,003)$; ОВ 27,1 мес против 9,3 мес $(p=0,008)$. Таким образом, формально доза леналидомида, при которой отмечается прогрессирование, особого значения не имеет. Однако это не совсем так. Если на момент прогрессирования пациент получал леналидомид без дексаметазона, все было бы гораздо лучше, чем если бы он получал полноценную схему Rd: медиана ВБП 20,6 мес против 4,8 мес ( $p=0,030)$; медиана ОВ не достигнута против 11,7 мес $(p=0,077)$. Личный опыт также показывает, что у пациентов с рецидивами, развившимися на фоне поддерживающего лечения леналидомидом 10-15 мг после аутологичной трансплантации гемопоэтических стволовых клеток или тем более после его окончания, наблюдается хороший ответ на новые триплеты на основе Rd.

Включение в схемы лечения моноклональных антител, нацеленных на специфические рецепторы на мембране опухолевых клеток и воздействие на $T$ - и NK-клетки пациента, является привлекательным подходом для пациентов с ММ, позволяющим получить стойкий и глубокий ответ даже у сильно предлеченных больных. Давайте обсудим это направление иммунотерапии ММ.

Моноклональные антитела являются очень эффективным средством лечения многих солидных и гематологических злокачественных опухолей. Первыми антигенами, которые были выбраны в качестве мишени для лечения MM, стали молекулы CD38 и SLAMF7.

Рецептор CD38 представляет собой трансмембранный многофункциональный гликопротеин, выраженная экспрессия которого наблюдается как на нормальных,

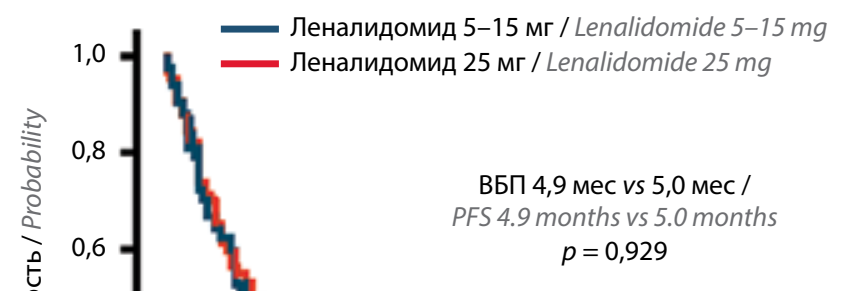

OB 11,9 мec vs 12,8 мес / OS 11.9 months vs 12.8 months $p=0,194$

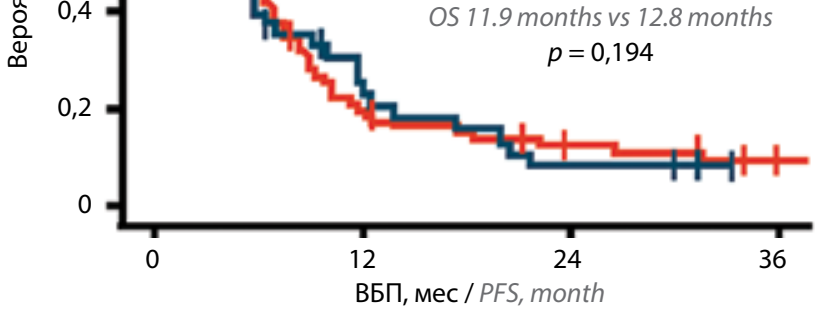

Леналидомид / Lenalidomide

$\begin{array}{lllll}5-15 \text { мг } & 52 & 11 & 3 & 0 \\ 25 \mathrm{Mг} & 95 & 17 & 8 & 4\end{array}$

Рис. 2. Выживаемость без прогрессирования (ВБП) в зависимости от последней дозы леналидомида (адаптировано из [11] с разрешения авторов). $О В$ - общая выживаемость

Fig. 2. Progression-free survival (PFS) according to last lenalidomide (adapted from [11] with permission of the authors). OS-overall survival 
так и на опухолевых плазматических клетках. Кроме того, слабая экспрессия CD38 определяется на других лимфоидных и миелоидных клетках, включая эритроциты и тромбоциты, а также на некоторых негемопоэтических клетках. CD38 действует как бифункциональный эктофермент, сочетающий в себе активность рибозилциклазы аденозиндифосфата (АДФ) и гидролазы циклической АДФ-рибозы (цАДФР), выполняющих функцию мобилизаторов кальция из внутриклеточного пространства [12]. Единственным известным несубстратным лигандом CD38 является рецептор CD31, который экспрессируется на клетках эндотелия. CD31 задействован в миграции лейкоцитов через эндотелиальную стенку.

Два моноклональных антитела (даратумумаб и изатуксимаб) настолько прочно вошли в нашу практику, что без них уже невозможно представить лечение ММ. Основными механизмами противоопухолевого действия анти-CD38-моноклональных антител являются:

- прямое цитотоксическое действие через индукцию апоптоза;

- иммуноопосредованный лизис опухолевых клеток посредством антителозависимой клеточно-опосредованной цитотоксичности, комплементзависимой цитотоксичности, индукции фагоцитоза или активации цитотоксических Т-клеток;

- воздействие на стромальное опухолевое микроокружение;

- подавление CD38-позитивных иммуносупрессорных клеток, включая регуляторные Т- и В-клетки, супрессорные клетки миелоидного происхождения (myeloid derived suppressor cells, MDSC) [13].

Рецептор SLAMF7 (CD319, CS1) - мембранный белок, входящий в семейство сигнальных лимфоцитарных молекул активации (signaling lymphocytic activation molecule, SLAM). Плотная экспрессия SLAMF7 характерна для миеломных плазматических клеток, NK-клеток и некоторых других иммунокомпетентных клеток. Моноклональное антитело против SLAMF7 элотузумаб показало высокую клиническую активность при ММ в комбинации с противоопухолевыми иммуномодуляторами (EloRd (элотузумаб, леналидомид, дексаметазон), EloPd (элотузумаб, помалидомид, дексаметазон)) [14].

Комбинации, построенные на основе моноклональных антител с особенностями целевых групп пациентов, представлены в таблице.

Триплеты EloRd, DaraRd (даратумумаб, леналидомид, дексаметазон), DaraVd (даратумумаб, бортезомиб, дексаметазон), DaraKd (даратумумаб, карфилзомиб, дексаметазон) и IsaKd (изатуксимаб, карфилзомиб, дексаметазон) больше подходят для лечения рецидивов после 1-2-й линий терапии. DaraKd и IsaKd можно рекомендовать в ранних линиях, особенно в случае известной рефрактерности к леналидомиду. Схемы на платформе Pd назначают для терапии 3-го и последующих рецидивов, поскольку они ориентированы на пациентов с двойной рефрактерностью.

Базовые схемы иммунохимиотерапии рецидивирующей/рефрактерной множественной миеломы Basic immunochemotherapy regimens for relapsed/refractory multiple myeloma

\begin{tabular}{|c|c|c|c|c|c|c|c|c|}
\hline \multirow{2}{*}{$\begin{array}{c}\text { Монокло- } \\
\text { нальное } \\
\text { антитело } \\
\text { Monoclonal } \\
\text { antibody }\end{array}$} & \multirow{2}{*}{$\begin{array}{c}\text { Базовый } \\
\text { дуплет } \\
\text { Basic } \\
\text { doublet }\end{array}$} & \multirow{2}{*}{$\begin{array}{c}\text { Количество } \\
\text { линий } \\
\text { предшествующей } \\
\text { терапии } \\
\text { Number of previous } \\
\text { therapy lines }\end{array}$} & \multicolumn{3}{|c|}{$\begin{array}{c}\text { Рефрактерность } \\
\text { Refractory }\end{array}$} & \multirow{2}{*}{$\begin{array}{l}\geq \Pi \mathrm{IP}, \% \\
\geq \mathrm{CR}, \%\end{array}$} & \multirow{2}{*}{$\begin{array}{c}\text { Медиана } \\
\text { ВБП, мес } \\
\text { Median } \\
\text { of PFS, } \\
\text { months }\end{array}$} & \multirow{2}{*}{$\begin{array}{c}\text { Литература } \\
\text { Reference }\end{array}$} \\
\hline & & & иП, \% & $\begin{array}{c}\text { Леналидо- } \\
\text { мид, \% } \\
\text { Lenalidomide, \% }\end{array}$ & $\begin{array}{c}\text { ИП + леналидо- } \\
\text { мид, \% } \\
\text { PI + lenalidomide, \% }\end{array}$ & & & \\
\hline \multirow{4}{*}{ Dara+ } & $\mathrm{Vd}$ & $\geq 1$ & - & 24 & - & 30 & 16,7 & [15] \\
\hline & $\mathrm{Rd}$ & $\geq 1$ & 21 & - & - & 57 & 45,0 & [16] \\
\hline & $\mathrm{Kd}$ & $1-2$ & 28 & 32 & 12 & 29 & 28,6 & [17] \\
\hline & $\mathrm{Pd}$ & $1-5$ & 47 & 79 & 42 & 25 & 12,4 & [18] \\
\hline \multirow{2}{*}{ Isa+ } & $\mathrm{Kd}$ & $1-4$ & 31 & 32 & 17 & 40 & $\begin{array}{l}\mathrm{H} / \text { д } \\
\mathrm{N} / \mathrm{a}\end{array}$ & [19] \\
\hline & $\mathrm{Pd}$ & $\geq 2$ & 77 & 94 & 72 & 5 & 11,5 & [20] \\
\hline \multirow{2}{*}{ Elo+ } & $\mathrm{Rd}$ & $1-4$ & 22 & - & - & 5 & 19,4 & [21] \\
\hline & $\mathrm{Pd}$ & $\geq 2$ & 78 & 90 & 68 & 8 & 10,3 & [22] \\
\hline
\end{tabular}

Примечание. ИП - ингибиторы протеасомы; ПР - полная ремиссия; ВБП - выживаемость без прогрессирования; Dага - даратумумаб; Isa - изатуксимаб; Elo - элотузумаб; Vd - бортезомиб, дексаметазон; Rd - леналидомид, дексаметазон; Kdкарфилзомиб, дексаметазон; Pd - помалидомид, дексаметазон; н/д - не достигнута.

Note. PI - proteasome inhibitors; CR - complete response; PFS - progression-free survival; Dara - daratumumab; Isa - isatuximab; Elo - elotuzumab; $V d$ - bortezomib, dexamethasone; $R d$-lenalidomide, dexamethasone; $K d$ - carfilzomib, dexamethasone; Pd-pomalidomide, dexamethasone; $n / a$ not achieved. 
В качестве новой стратегии лечения $М$ М, помимо ставших уже привычными моноклональных антител против CD38 и SLAMF7, рассматривается воздействие на опухолевые клетки через антиген созревания B-клеток (B cell maturation antigen, ВCMA). Что это за молекула и как она участвует в патогенезе ММ?

Антиген созревания В-клеток, также называемый 17-м участником суперсемейства рецепторов фактора некроза опухоли (TNFRS17), представляет собой трансмембранный белок, лишенный сигнального участка и содержащий богатые цистеином внеклеточные домены [23]. ВСМА вместе с двумя родственными рецепторами BAFF-R и TACI является критически важным регулятором пролиферации и выживания В-клеток, определяющим их созревание и дифференцировку в плазматическую клетку. Все 3 указанных рецептора поддерживают долгосрочное выживание В-клеток на разных стадиях развития. Экспрессия ВСМА появляется на поздних этапах дифференцировки В-клеток, когда они уже коммитированы в сторону антителогенеза. В момент трансформации В-лимфоцита в плазмоцит экспрессия ВСМА увеличивается, a BAFF-R, наоборот, снижается [24]. Плотность экспрессии ВСМА на миеломных клетках существенно выше, чем на нормальных плазматических клетках, что делает этот антиген очень привлекательным для таргетной иммунотерапии. В результате действия $\gamma$-секретаз мембранная форма ВСМА расщепляется, что приводит к образованию растворимой формы BCMA (sBCMA) [25]. Определение данной молекулы в сыворотке крови, как оказалось, имеет важное значение, в частности для прогностической оценки эффективности ВСМА-направленной терапии [26].

В настоящее время уже используются в клинической практике либо находятся на разных стадиях клинических исследований 3 варианта ВСМА-направленной терапии (рис. 3).

Конгюгаты моноклонального антитела с лекарственными препаратами (antibody-drug conjugate, $A D C$ ) оказались успешным подходом в лечении лимфомы Ходжкина, CD30-позитивных неходжкинских лимфом (брентуксимаб ведотин) и острого миелоидного лейкоза (гемтузумаб озогамицин). Многие другие препараты находятся на разных этапах клинических исследований. В 2020 г. Управление по санитарному надзору за качеством пищевых продуктов и медикаментов США (FDA) зарегистрировало белантамаб мафодотин для лечения РРММ. Некоторые наши коллеги в России уже познакомились с этим препаратом, участвуя в клинических исследованиях. Каковы перспективы такого подхода, и что уже известно об эффективности белантамаба мафодотина?

Применение ADC представляет собой многообещающий подход, позволяющий, с одной стороны, использовать высокую специфичность моноклонального антитела к молекулам-мишеням на опухолевых клетках и, с другой стороны, фатально повредить их с помощью конъюгированных цитотоксинов. В идеальной ситуации ADC должны оставаться интактными в системном кровотоке. Цитотоксический агент отсоединяется от транспортирующего их антитела только после попадания в цитоплазму клетки-мишени.

Белантамаб мафодотин - первое в своем классе моноклональное антитело против ВСМА, конъюгированное с ингибитором полимеризации тубулина монометилауристатином F (MМAF). В исследовании II фазы 196 пациентов с РРММ были рандомизированы для получения 2,5 или 3,4 мг/кг белантамаба мафодотина [27]. Медиана предшествующих линий терапии составляла
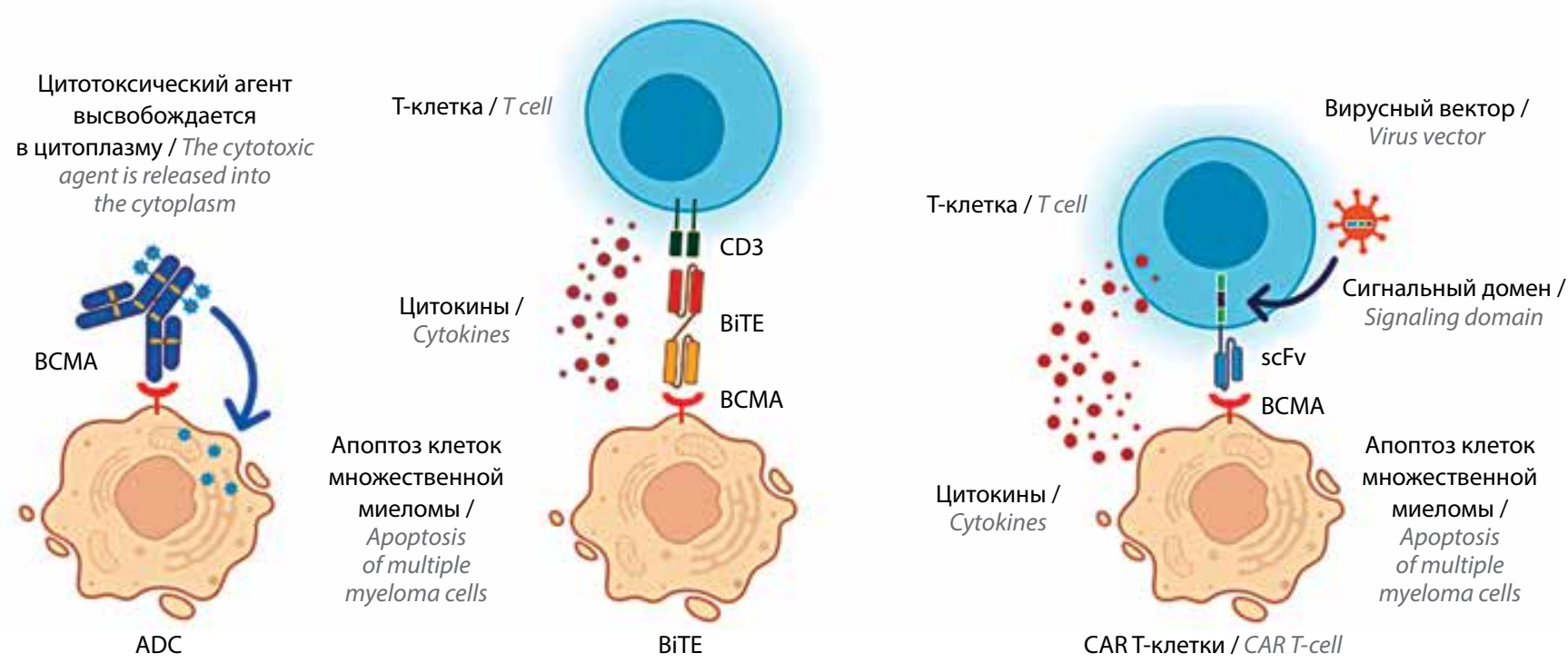

Рис. 3. Сравнение подходов иммунотерапии множественной миеломы: конбюгаты моноклонального антитела с лекарственными препаратами (ADC); биспецифические антитела, привлекающие T-клетки (ВіTE), и CAR T-клеточная терапия (адаптировано из [28] с разрешения авторов). CAR - химерный антигенный рецептор; ВСМА - антиген созревания В-клеток

Fig. 3. Comparison of antibody-drug conjugates (ADC), bispecific T-cell engagers (BiTE) and CAR T-cell construct immuno-oncology approaches in multiple myeloma (adapted from [28] with permission of the authors). CAR - chimeric antigen receptor; BCMA - B cell maturation antigen 
7 и 6 соответственно. Более $80 \%$ пациентов получили 4 линии терапии и более, включая ингибиторы протеасом, иммуномодуляторы и анти-CD38-антитела. Частота объективного ответа (ЧОО) составила $31 \%$ в когорте 2,5 мг/кг и $34 \%-3,4$ мг/кг. Самыми частыми нежелательными явлениями $\geq$ III степени были кератопатия (27 и $21 \%$ соответственно), тромбоцитопения (20 и $33 \%$ ), анемия (20 и $40 \%$ ) и инфузионные реакции (21 и $16 \%$ ). Офтальмологическая токсичность проявлялась нечеткостью зрения и сухостью глаз. Механизм повреждения роговицы, вероятно, связан с неспецифическим поглошением MMAF активно делящимися эпителиальными клетками роговицы. Глазные капли с кортикостероидами для профилактики неэффективны. Среднее время восстановления зрения составило 71 и 96 дней после завершения терапии. О стойкой потере зрения не сообщалось. Для применения была одобрена меньшая доза белантамаба мафодотина 2,5 мг/кг с введением препарата каждые 3 нед.

Еще одной опиией иммунотерапии, предложенной для лечения ММ, является непосредственное воздействие на Т-клетки пациента в целях активации их противоопухолевой активности. Что можно сказать про эту область клинических исследований при ММ?

Селективное направление активности Т-лимфоцитов против опухолевых клеток открывает большие перспективы лечения гематологических опухолей. В этой области существует еще 2 подхода иммунотерапии ММ (см. рис. 3). Первый - это конструирование аутологичных или аллогенных Т-клеток с интегрированным в них химерным антигенным рецептором (CAR T-клетки), способных распознавать опухолевые клетки, и второй - создание биспецифических антител, которые могут физически связывать между собой цитотоксические Т-лимфоциты и опухолевые клетки. Биспецифические антитела должны распознавать одновременно 2 разных антигена. В качестве таргетного эпитопа на Т-клетках был выбран рецептор CD3 [29]. Результатом межклеточного взаимодействия является активация Т-лимфоцита против опухолевой клетки. Иммунный ответ в данном случае не ограничен рецепторами главного комплекса гистосовместимости, поскольку это аутологичные Т-клетки, и не требует дополнительной костимуляции. В отличие от CAR T-клеток, биспецифические антитела представляют собой готовый лекарственный препарат, не требующий запуска производственного процесса для индивидуальных пациентов.

На каком этапе исследований находятся биспецифические антитела для лечения ММ и какие другие молекулярные мишени, помимо ВСМА, рассматриваются в качестве приоритетных?

Несколько препаратов этой группы полностью прошли I фазу исследований, однако одобрения для применения препаратов этой группы для лечения ММ пока нет.
Теклистамаб (Janssen) - гуманизированное биспецифическое антитело против BCMA/CD3. В исследовании MajesTEC-1 (фаза I/II) оптимальную дозу 1500 мкг/кг получили 159 пациентов с РРММ. Медиана линий предшествующей терапии была равна 5 (2-15). Рефрактерность к 3 классам препаратов имела место в $77 \%$ случаев. Эффективность терапии оценена у 40 пациентов, участвовавших в I фазе этого исследования. ЧОО составила $65 \%$, включая 40 \% полных и более глубоких ответов ( $\geq \mathrm{CR}$ (complete response)). Самыми частыми нежелательными явлениями были миелосупрессия, синдром высвобождения цитокинов (СВЦ) - $67 \%$ (99\% - I-II степеней), эритема в месте инъекции и слабость. У 4 (2,5\%) из 159 пациентов возникла неврологическая токсичность также в пределах I-II степеней тяжести [30]. По результатам исследования I фазы теклистамаб получил статус терапии прорыва (FDA, CША) и PRIME (приоритетное лекарство) по мнению Европейского агентства по лекарственным средствам (ЕMA). Регистрация препарата FDA ожидается уже в 2022 г.

AMG 701 (Amgen) - еще одно биспецифическое антитело против BCMA/CD3, также прошло I фазу клинических исследований с участием 75 пациентов с РРММ. Это были сильно предлеченные пациенты с медианой линий терапии $6(1-25)$ и рефрактерностью к 3 классам препаратов в $68 \%$ случаев. ЧОО составила $36 \%$ для пациентов, получивших AMG 701 в дозе от 3 до 12 мг, и $83 \%$ в случае ранней эскалации дозы до 9 мг. Самыми частыми нежелательными явлениями были цитопении, СВЦ (61 \%), диарея, слабость и лихорадка. СВЦ ІІІ степени тяжести имел место у 5 пациентов и рассматривался как дозолимитирующая токсичность [31].

TNB-383B (AbbVie) структурно отличается от вышепредставленных препаратов двумя доменами против ВСМА вместо одного, чтобы повысить тропность антитела к мембранному рецептору и уменьшить к растворимому с целью ограничить системную реакцию высвобождения цитокинов [32]. Изменение структуры антитела привело к пролонгированию периода полувыведения, что позволяет вводить препарат каждые 3 нед, в отличие от еженедельного для теклистамаба и AMG 701. ЧОО в исследовании I фазы для 60 пациентов, получивших препарат в дозе $\geq 40$ мг, составила $79 \%$, включая 29 \% CR. В общей группе пациентов СВЦ имел место у 54 (52 \%) из 103 больных, включая 1 случай III степени тяжести.

Помимо биспецифических антител к BCMA/CD3, на стадии ранних клинических исследований находятся еще 2 препарата. Талкетамаб (Janssen) - новое биспецифическое антитело против рецептора GPRC5D на миеломных клетках и CD3 на Т-лимфоцитах. Уникальность антигена GPRC5D (участник D группы 5 семейства C рецепторов, связанных с G-белками) определяется тем, что он экспрессируется исключительно на миеломных клетках и нормальных клетках 
волосяных фолликулов [33]. ЧОО составила $71 \%$. СВЦ имел место в $73 \%$ случаев. Из необычных побочных явлений были проблемы с ногтями (30 \%) [34]. Цевостамаб (Hoffmann-La Roche) - биспецифическое антитело против FcRH5 и CD3. Антиген FcRH5 является уникальным В-линейным маркером, экспрессия которого сохраняется на плазматических клетках. ЧОО у пациентов, получавших целевую дозу $\geq 20$ мг $(n=34)$, составила $53 \%$. СВЦ развился в $76 \%$ случаев [35].

Несомненно, самым интригующим методом иммунотерапии гематологических опухолей является терапия CAR T-клетками. Какова эффективность этого метода в лечении ММ?

В 2021 г. идекабтаген виклеусел (Абекма, Bristol Myers Squibb) получил одобрение FDA и EMA в качестве CAR T-клеточной терапии. Это первый препарат данного класса для лечения ММ.

Идекабтаген виклеусел был зарегистрирован по результатам исследования KarMMa (II фаза), в котором принимали участие 128 пациентов с РРММ, получивших до этого не менее 3 линий терапии, включая иммуномодулирующие средства, ингибитор протеасомы и антитела к CD38 [36]. ЧОО составила $73 \%$, и при этом $33 \%$ пациентов достигли полного или более глубокого ответа $(\geq \mathrm{CR})$. Отрицательный статус по минимальной остаточной болезни (МОБ) $\left(10^{-5}\right)$ был подтвержден у 26 \% больных. Эффект носит дозозависимый характер. ЧОО у пациентов, получивших препарат в дозе $150 \times 10^{6}$ клеток, составила $50 \%$, $300 \times 10^{6}$ клеток $-69 \%$ и $450 \times 10^{6}$ клеток $-81 \%$. Результаты исследования биомаркеров показали, что снижение концентрации sBCMА в сыворотке крови коррелировало с глубиной ответа. Медиана ВБП составила 8,8 мес (95\% ДИ 5,6-11,6 мес), ОВ 19,4 мес (18,2 - не достигнута). Длительность ответа коррелировала с его глубиной (рис. 4).

Наиболее частыми побочными эффектами были нейтропения (91\%), СВЦ (84\%), анемия (70\%) и тромбоцитопения (63\%). У 7 (5\%) пациентов СВЦ был ІІІ степени или выше. Проявления нейротоксичности имели место в 23 (18 \%) случаях, включая 4 (3\%) - III степени тяжести.

Цилтакабтаген аутолейцел - еще один препарат CAR T-клеточной терапии MM, разработанный объединенными усилиями Janssen и Legend Biotech. Сконструированный химерный рецептор содержит два ВСМА-связывающих эпитопа (для повышения авидности), костимулирующий 4-1ВВ и сигнальный домен CD3z. В исследовании CARTITUDE-1 (фаза Ib/II) участвовали 97 пациентов с РРММ [37]. Это была когорта сильно предлеченных пациентов с медианой количества линий терапии, равной 6 (3-18), и рефрактерностью к 3 классам препаратов в $88 \%$ случаев. ЧОО составила $98 \%$, включая $80 \%$ случаев достижения строго полного ответа. МОБ-отрицательный ответ $\left(10^{-5}\right)$ был получен у $92 \%$ больных и сохранялся $\geq 12$ мес в $18 \%$ случаев.

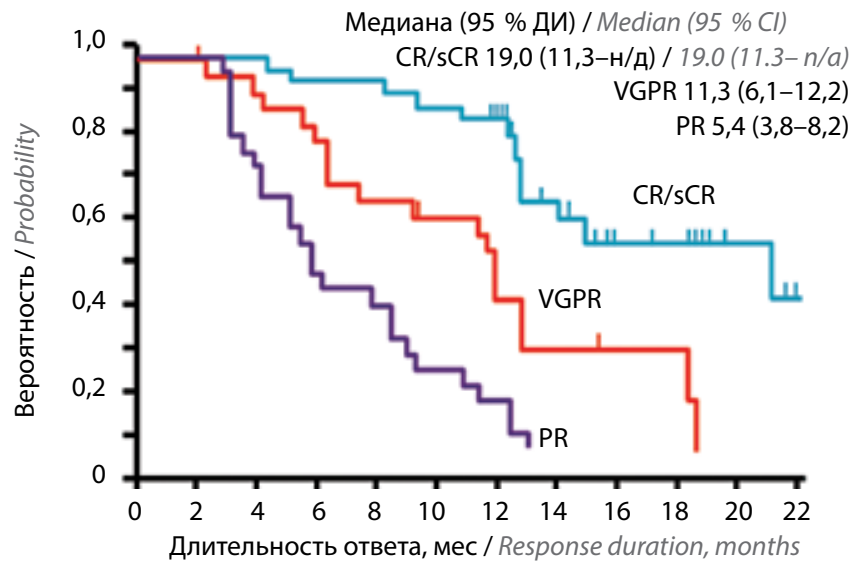

Рис. 4. Длительность ответа на CAR T-клеточную терапию (идекабтаген виклеусел) в соответствии с его глубиной (адаптировано из [36] c разрешения авторов). CR - полный ответ; $s C R-$ строгий полный ответ; VGPR - очень хороший частичный ответ; PR - частичный ответ; ДИ-доверительный интервал; н/д - не достигнута

Fig. 4. Duration of response for CAR T-cell therapy (idecabtagene vicleucel) according to best response (adapted from [36] with permission of the authors). CR complete response; $s C R$ - strong complete response; VGPR - very good partial response; $P R$ - partial response; $C I$ - confidence interval; $n / a$ - not achieved

ВБП и ОВ за 18 мес составили 66 и $81 \%$ соответственно. Самыми частыми нежелательными явлениями IIIIV степени тяжести были нейтропения (95\%), анемия (68\%), тромбоцитопения (60\%) и лимфопения $(49,5 \%$ случаев). СВЦ возник у $95 \%$, а нейротоксичность у 16,5 \% пациентов. Один пациент после прогрессирования повторно получил цилтакабтаген аутолейцел, была достигнута стабилизация.

При анализе этих 2 представленных препаратов обращает на себя внимание отсутствие плато на кривых выживаемости. Таким образом, несмотря на ошеломляющую частоту МОБ-отрицательных ответов, излечение PPMМ с помощью CAR T-клеточной терапии пока невозможно. Важно продолжать исследования и совершенствовать технологию.

Данные по CAR T-клеточной терапии МM действительно впечатляют, но давайте обсудим некоторые практические аспекты применения данной технологии. Как долго длится технологический процесс производства инженерных T-лимфоцитов? Это важно, поскольку у сильно предлеченных пациентов часто наблюдается очень быстрое прогрессирование и они не могут долго пребывать вне лечения.

В зависимости от конкретного клеточного продукта время производства занимает в среднем 17-28 дней. Это время от момента афереза лейкоцитов до возвращения из лаборатории готовых CAR T-клеток и начала проведения пациенту лимфодеплеции, предшествующей реинфузии их пациенту. В реальной практике вне клинических исследований эти сроки могут только увеличиваться. На протяжении указанного отрезка времени можно успеть провести пациенту очередной курс химиотерапии для предупреждения быстрого прогрессирования. В одном из исследований была 
показана польза терапии леналидомидом непосредственно перед CAR T-клеточной терапии [38].

Применение CAR T-клеток и биспецифических антител, привлекающих T-клетки (bispecific T-cell engagers, ВіTE), часто сопровождается проявлениями острой токсичности. Прежде всего обращает на себя внимание то, что почти у всех пациентов возникает СВЦ. Как быстро он возникает и какие способы его лечения разработаны?

Синдром высвобождения цитокинов обычно развивается через 2-3 дня после введения CAR T-клеток и длится около 7-8 дней. Клинические симптомы включают лихорадку, озноб, повышение артериального давления, тахикардию и развитие гипоксии. Симптомы могут варьировать от едва заметных до угрожающих жизни гипотензии и дыхательной недостаточности. В крайней форме системный воспалительный ответ реализуется как фульминантный гемофагоцитарный лимфогистиоцитоз/синдром активации макрофагов (HLH/MAS), ассоциирующийся с очень высокой смертностью [39]. Существует очевидная взаимосвязь между объемом опухолевой массы и тяжестью СВЦ. Лечение включает назначение антипиретиков, дексаметазона, адекватную гидратацию и введение тоцилизумаба для блокирования интерлейкина 6.

Что можно сказать про нейротоксичность СAR Tклеточной терапии и ВіTE?

Синдром нейротоксичности, ассоциированный с иммунными эффекторными клетками (ICANS) обычно возникает через 4-10 дней, немного запаздывая от начала СВЦ [40]. Продолжительность составляет в среднем 14-17 дней. Клинически ICANS проявляется спутанностью сознания, афазией, бредом, судорогами, энцефалопатией и повышением внутричерепного давления. Патофизиология этого состояния включает активацию эндотелия с повреждением гематоэнцефалического барьера, модуляцию эндогенных агонистов NMDA-рецепторов, воздействие на центральную нервную систему провоспалительных цитокинов с последующей активацией Т-лимфоцитов и миелоидных клеток. Лечение предполагает применение противосудорожных препаратов и глюкокортикостероидов.

Глубокоуважаемый Сергей Вячеславович! Разрешите поблагодарить Вас за интересную беседу! Мы обсудили важные моменты, касающиеся практических аспектов применения противоопухолевых иммуномодуляторов. Это очень важно, поскольку иммуномодулятор 3-го поколения помалидомид вошел с 2022 г. в программу ВЗН, обеспеченную государственными гарантиями. Возможно, что не все врачи пока имеют собственный опыт применения данного препарата. Кроме того, мы обсудили все другие опции иммунотерапии, начиная от моноклональных антител против CD38 и SLAMF7 и заканчивая технологией CAR T-клеточной терапии.

\section{Интервью брала П.А. Зейналова, д.м.н., профессор (Клинический госпиталь «Лапино» группы компаний «Мать и дитя», \\ ФГАОУ ВО Первый Московский государственный медицинский университет им. И.М. Сеченова Минздрава России (Сеченовский Университет))}

\section{Л И Т E P A T У $P$ A / RE F E RE N C E S}

1. Менделеева Л.П., Савченко В.Г., Паровичникова Е.Н. и др. Анализ трансплантационной активности в РФ за 2018 г. (отчет межрегионального регистра). Гематология и трансфузиология 2020;65(S1):180. [Mendeleeva L.P., Savchenko V.G., Parovichnikova L.P. et al. Analysis of transplantation activity in the Russian Federation for 2018 (report of the interregional register).

Gematologiya i transfuziologiya $=$ Russian Journal of Hematology and Transfusiology 2020;65(S1):180. (In Russ.)].

2. Семочкин С.В. Терапия рецидивирующей и рефрактерной множественной миеломы, отягощенной двойной рефрактерностью (обзор литературы). Онкогематология 2021;16(3):58-73. [Semochkin S. V. Treatment of doublerefractory multiple myeloma. Onkogematologiya = Oncohematology 2021;16(3): 58-73. (In Russ.)]. DOI: 10.17650/18188346-2021-16-3-58-73.

3. Kim C., Braunlin M., Mehta B., Payne R. Outcomes of triple-class (proteasome inhibitor, immunomodulator, cd38 monoclonal antibody) exposed relapsed or refractory multiple myeloma (RRMM) in United States (US) real-world practice. Blood 2021;138(Suppl 1):3042. DOI: 10.1182/blood-2021-145588.

4. Семочкин С.В. Биологические основы применения иммуномодулирующих препаратов в лечении множественной миеломы. Онкогематология 2010;(1): 21-31. [Semochkin S.V. Biological fundamentals of application of immunomodulatory agents in treatment of multiple myeloma. Onkogematologiya $=$ Oncohematology 2010;(1):21-31. (In Russ.)].

5. Dimopoulos M., Leleu X., Palumbo A. et al. Expert panel consensus statement on the optimal use of pomalidomide in relapsed and refractory multiple myeloma. Leukemia 2014;28(8):1573-85. DOI: 10.1038/leu.2014.60.

6. Ludwig H., Boccadoro M., Moreau P. et al. Recommendations for vaccination in multiple myeloma: a consensus of the European Myeloma Network Leukemia 2021;35(1):31-44. DOI: 10.1038/s41375-020-01016-0.
7. Dechow T., Aldaoud A., Behlendorf T. et al. Pomalidomide plus dexamethasone for patients with relapsed or refractory multiple myeloma: final results of the noninterventional study POSEIDON and comparison with the pivotal phase 3 clinical trials. Eur J Haematol 2022;108(2): 133-44. DOI: 10.1111/ejh.13719.

8. Lacy M.Q., Hayman S.R., Gertz M.A. et al. Pomalidomide (CC4047) plus lowdose dexamethasone as therapy for relapsed multiple myeloma. J Clin Oncol 2009;27(3):5008-14. DOI: 10.1200/JCO.2009.23.6802.

9. Lacy M.Q., Hayman S.R., Gertz M.A. et al. Pomalidomide (CC4047) plus low dose dexamethasone (Pom/dex) is active and well tolerated in lenalidomide refractory multiple myeloma (MM). Leukemia 2010;24(11):1934-99. DOI: 10.1038/leu.2010.190.

10. Lacy M.Q., Allred J.B., Gertz M.A. et al. Pomalidomide plus low-dose dexamethasone in myeloma refractory to both bortezomib and lenalidomide: comparison of 2 dosing strategies in dual- 
refractory disease. Blood

2011;118(11):2970-5.

DOI: 10.1182/blood-2011-04-348896.

11. Kastritis E., Roussou M., Gavriatopoulou M. et al. Impact of last lenalidomide dose, duration, and IMiD-free interval in patients with myeloma treated with pomalidomide/dexamethasone. Blood Adv 2019;3(23):4095-103.

DOI: 10.1182/bloodadvances.2019000539.

12. Hogan K.A., Chini C.C.S., Chini E.N. The multi-faceted ecto-enzyme CD38: roles in immunomodulation, cancer, aging, and metabolic diseases. Front Immunol 2019;10:1187. DOI: 10.3389/fimmu.2019.01187.

13. Van de Donk N. Immunomodulatory effects of CD38-targeting antibodies. Immunol Lett 2018;199:16-22. DOI: 10.1016/j.imlet.2018.04.005.

14. Campbell K.S., Cohen A.D., Pazina T. Mechanisms of NK cell activation and clinical activity of the therapeutic SLAMF7 antibody, elotuzumab in multiple myeloma. Front Immunol 2018;9:2551. DOI: 10.3389/fimmu.2018.02551.

15. Mateos M.V., Sonneveld P., Hungria V. et al. Daratumumab, bortezomib, and dexamethasone versus bortezomib and dexamethasone in patients with previously treated multiple myeloma: threeyear follow-up of CASTOR. Clin Lymphoma Myeloma Leuk. 2020;20(8): 509-18. DOI: 10.1016/j.clml.2019.09.623.

16. Bahlis N.J., Dimopoulos M.A., White D.J. et al. Daratumumab plus lenalidomide and dexamethasone in relapsed/refractory multiple myeloma: extended follow-up of POLLUX, a randomized, open-label, phase 3 study. Leukemia 2020;34(7):1875-84. DOI: 10.1038/s41375-020-0711-6.

17. Dimopoulos M., Quach H., Mateos M.V., et al. Carfilzomib, dexamethasone, and daratumumab versus carfilzomib and dexamethasone for patients with relapsed or refractory multiple myeloma (CANDOR): results from a randomised, multicentre, open-label, phase 3 study. Lancet 2020;396(10245):186-97. DOI: 10.1016/S0140-6736(20)30734-0.

18. Dimopoulos M.A., Terpos E., Boccadoro M. et al. Daratumumab plus pomalidomide and dexamethasone versus pomalidomide and dexamethasone alone in previously treated multiple myeloma (APOLLO): an open-label, randomised, phase 3 trial. Lancet Oncol 2021;22(6):801-12. DOI: 10.1016/S1470-2045(21)00128-5.

19. Moreau P., Dimopoulos M.A., Yong K. et al. Isatuximab plus carfilzomib/ dexamethasone versus carfilzomib/ dexamethasone in patients with relapsed/ refractory multiple myeloma: IKEMA Phase III study design. Future Oncol 2020;16(2):4347-58 DOI: $10.2217 /$ fon-2019-0431

20. Attal M., Richardson P.G., Rajkumar S.V. et al. Isatuximab plus pomalidomide and low-dose dexamethasone versus pomalidomide and low-dose dexamethasone in patients with relapsed and refractory multiple myeloma (ICARIA-MM): a randomised, multicentre, open-label, phase 3 study. Lancet 2019;394(10214):2096-107. DOI: 10.1016/S0140-6736(19)32556-5

21. Dimopoulos M.A., Lonial S., White D. et al. Elotuzumab, lenalidomide, and dexamethasone in RRMM: final overall survival results from the phase 3 randomized ELOQUENT-2 study. Blood Cancer J 2020;10(9):91. DOI: 10.1038/s41408-020-00357-4.

22. Dimopoulos M.A., Dytfeld D., Grosicki S. et al. Elotuzumab plus pomalidomide and dexamethasone for multiple myeloma. Engl J Med 2018;379(19):1811-22. DOI: 10.1056/NEJMoa1805762.

23. Shah N., Chari A., Scott E. et al. B-cell maturation antigen (BCMA) in multiple myeloma: rationale for targeting and current therapeutic approaches. Leukemia 2020;34(4):985-1005. DOI: 10.1038/s41375-020-0734-z.

24. Novak A.J., Darce J.R., Arendt B.K. et al. Expression of BCMA, TACI and BAFF-R in multiple myeloma: a mechanism for growth and survival. Blood 2004;103(2):689-94. DOI: 10.1182/blood-2003-06-2043.

25. Pont M.J., Hill T., Cole G.O. et al. Gamma-Secretase inhibition increases efficacy of BCMA-specific chimeric antigen receptor $T$ cells in multiple myeloma. Blood 2019;134(19):1585-97. DOI: 10.1182/blood.2019000050.

26. Jew S., Chang T., Bujarski S. et al. Normalization of serum B-cell maturation antigen levels predicts overall survival among multiple myeloma patients starting treatment. Br J Haematol 2021;192(2): 272-80 DOI: $10.1111 /$ bjh. 16752 .

27. Lonial S., Lee H.C., Badros A. et al. Belantamab mafodotin for relapsed or refractory multiple myeloma (DREAMM-2): a two-arm, randomised, open-label, phase 2 study. Lancet Oncol 2020;21(2):207-21 DOI: 10.1016/S1470-2045(19)30788-0.

28. Cohen A.D., Raje N., Fowler J.A. et al. How to train your T cells: overcoming immune dysfunction in multiple myeloma. Clin Cancer Res 2020;26(7):1541-54. DOI: 10.1158/1078-0432.CCR-19-2111.

29. Lejeune M., Köse M.C., Duray E. et al. Bispecific, T-cell-recruiting antibodies in B-cell malignancies. Front Immunol 2020; 11:762. DOI: 10.3389/ fimmu.2020.00762.

30. Moreau P., Usmani S.Z., Garfall A.L. et al. Updated results from MajesTEC-1: phase $1 / 2$ study of Teclistamab, a B-cell maturation antigen $\mathrm{x} C \mathrm{CD} 3$ bispecific antibody, in relapsed/refractory multiple myeloma. Blood 2021;138(S1):896. DOI: 10.1182/blood-2021-147915.
31. Harrison S.J., Minnema M.C., Lee H.C. et al. A Phase 1 First in Human (FIH) study of AMG 701, an Anti-B-Cell Maturation Antigen (BCMA) Half-Life Extended (HLE) BiTE ${ }^{\circledR}$ (bispecific T-cell engager) molecule, in Relapsed/Refractory (RR) Multiple Myeloma (MM). Blood 2020;136(S1):28-9.

DOI: 10.1182/blood-2020-134063.

32. Kumar S., D'Souza A., Shah N. et al. A phase 1 first-in-human study of Tnb-383B, a BCMA x CD3 bispecific T-Cell redirecting antibody, in patients with relapsed/refractory multiple myeloma. Blood 2021;138(Suppl 1):900. DOI: 10.1182/blood-2021-150757.

33. Pillarisetti K., Edavettal S., Mendonça M. et al. A T-cell-redirecting bispecific Gprotein-coupled receptor class 5 member D x CD3 antibody to treat multiple myeloma. Blood 2020;135(15):1232-43. DOI: 10.1182/blood.2019003342.

34. Krishnan A.Y., Monique C., Minnema M.C. et al. Updated Phase 1 results from MonumenTAL-1: first-in-human study of Talquetamab, a $\mathrm{G}$ protein-coupled receptor family $\mathrm{C}$ group 5 member $\mathrm{D} x$ CD3 bispecific antibody, in patients with relapsed/refractory multiple myeloma. Blood 2021;138(S1):158. DOI: 10.1182/blood-2021-146868.

35. Cohen A.C., Harrison S.J., Krishnan A. et al. Initial clinical activity and safety of BFCR4350A, a FcRH5/CD3 T-Cellengaging bispecific antibody, in relapsed/ refractory multiple myeloma. Blood 2020;136(S1):42-3.

DOI: 10.1182/blood-2020-136985.

36. Munshi N.C., Anderson L.D. Shah N. et al. Idecabtagene vicleucel in relapsed and refractory multiple myeloma. N Engl J Med 2021;384(8):705-16. DOI: 10.1056/NEJMoa2024850.

37. Martin T., Usmani S.Z., Berdeja J.G. et al. Updated results from CARTITUDE-1: PHASE 1B/2STUDY of Ciltacabtagene Autoleucel, a B-cell maturation antigendirected chimeric antigen receptor $\mathrm{T}$ cell therapy, in patients with relapsed/refractory multiple myeloma. Blood 2021:138(S1):549. DOI: 10.1182/blood-2021-146060.

38. Zhang L., Jin G., Chen Z. et al. Lenalidomide improves the antitumor activity of CAR-T cells directed toward the intracellular Wilms Tumor 1 antigen. Hematology 2021;26(1):818-26. DOI: $10.1080 / 16078454.2021 .1981534$.

39. Martín-Rojas R.M., Gómez-Centurión I., Bailén R. et al. Hemophagocytic lymphohistiocytosis/macrophage activation syndrome (HLH/MAS) following treatment with tisagenlecleucel. Clin Case Rep 2022;10(1):e05209. DOI: $10.1002 / \mathrm{ccr} 3.5209$.

40. Möhn N., Bonda V., Grote-Levi L. et al. Neurological management and work-up of neurotoxicity associated with CAR T cell therapy. Neurol Res Pract 2022;4(1):1. DOI: $10.1186 / \mathrm{s} 42466-021-00166-5$. 